TRAMES, 2015, 19(69/64), 1, 15-34

\title{
EMIC CONCEPTUALIZATION OF A 'WILD EDIBLE PLANT' IN ESTONIA IN THE SECOND HALF OF THE 20TH CENTURY
}

\author{
Renata Sõukand and Raivo Kalle
}

Estonian Literary Museum

\begin{abstract}
Understanding the emic concept of wild edible plants in specific cultural settings is important to map local perceptions on nature. As there is no specific word to describe the concept of a wild edible plant in Estonian, we asked to list plants belonging to a category described by two partly overlapping phrases: looduslik taim (natural plant) and metsikult kasvav taim (plant that grows wild). Answers of 85 lay respondents were analysed quantitatively based on the nomenclature of the plants listed and qualitatively based on the question requiring narrative responce. While in the Estonian realm of the second half of the 20th century there was no need for conceptualization of wild (edible) plants and the notion did not exist, people describe them through the ability to grow itself, opposing to cultivation, places of growing, and higher level of abstraction. Prototypes of wild edible plants were Oxalis acetosella, Rumex acetosa, Fragaria vesca and Vaccinium myrtillus.
\end{abstract}

Keywords: wild edible plants, ecosemiotics, conceptualization, historical ethnobotany, Estonia

DOI: $10.3176 /$ tr.2015.1.02

\section{Introduction}

Wild edible plants have been a popular research subject in ethnobotany. Numerous recent publications have reflected on the use of wild edible plants in Europe through historical research based on archival data (for example see Łuczaj 2008, Łuczaj and Szymański 2007), modern fieldworks conducted in indigenous, isolated, rural or even urbanized regions (Tardío et al. 2005, Redžić 2010, Pieroni et al. 2005). Several regional and national European, but also international reviews of wild edibles have also been recently published (Redžić 2006, Tardío et al. 2006, Tardío 2010, Turner et al. 2011, Łuczaj 2012, Denes et al. 2012, Kalle and Sõukand 2012, Molina et al. 2014). Altogether, the number of articles in all data- 
bases of the Web of Science that return to the search topic "wild edible plants ethnobotany" is to 122 titles (28.04.2014). Scientific books (for example Etkin 1994, Etkin 2006) and special issues of journals are dedicated to the subject. The interest toward wild food plants is well justified, as they can provide valuable nutrients and several health benefits (Sánchez-Mata et al. 2012). Hence the studies of wild edibles are often merged with the studies of medicinal plants (Pieroni et al. 2002a, Pieroni and Quave 2006, Sõukand and Kalle 2013, Pieroni et al. 2014, Quave and Pieroni 2014).

The majority of ethobotanical studies define the domain of wild edible plants through the etic perspective, in order to be understandable within the discipline, to other researchers. Often, such definition is made to simply underline the principles of inclusion of plants into this particular study. For example, wild plant is defined through the habitat without secondary disturbance (Logan and Dixon 1994) or as being neither managed nor cultivated (Dufour and Wilson 1994, Molina et al. 2014), often acknowledging the situation of 'wild' on just one side of the continuum of plant-human relationship, e.g. the level of the domestication of the plants. On the other hand, in their review on the literature of internationally used wild food plants, Turner et al. (2011) consider 'wild edibles' only those plants that are gathered without 'particular manipulation', admitting however, that all wild resources are manipulated at least in some extent.

In case of participatory research, e.g. face-to face fieldworks, which is classical research method in ethnobotany, the explicit need for the understanding of folk perception of wild edible plant barely exists. In the field, the interviewed persons guide researchers to the plants they use, rarely attributing it routinely into specific domains which do not relate to its use, unless it is explicitly asked. It is the responsibility of the researcher to determine whether a definite plant belongs to wild or cultivated category based on the flora of a specific region and disciplinarily agreed etic perception of what can be considered a wild edible plant.

Research on wild food plants, which is the part of Local Ecological Knowledge, is, among other goals, intended to help local communities to value and preserve their knowledge, develop better practices in environment conservation and foster economic development of the communities (for example by promoting small-scale enterprises based on the use of natural resources). Understanding the perception of wild plants within specific researched population would add an important insight onto the cognition of the domain and would help the researchers to formulate the questions in order to receive maximal results from the interview. Hence there have been few attempts to add to the etic domain of wild edible plants some emic perspective, including native and also naturalized species, but also providing some emic insights of lay folk perceptions of 'wildness' of specific species, associating it rather with gathering, not farming (for example see Łuczaj et al. 2012, MenedezBaceta et al. 2012) or on specific category within the domain of wild edible plants, like ta chorta (wild edible greens) in Graecanic area in Calabria, Southern Italy (Nebel et al. 2006) or liakra (wild bitter greens) of Albanian diaspora living in Southern Italy (Pieroni et al. 2002b). Moreover, a few recent articles analyse the 
domain of wild plants from the respondents' perspective, noting that villagers' conceptualization of 'wild' depends on the ability of the plant to 'birth itself' or "to regenerate itself ... despite any management activity that may be applied to it", excluding domesticates that can run wild, but stressing that "utilization of emic, concerning local cognitive systems, is an important starting point for research on the process of domestication" (Cruz-Garcia and Price 2011:5, Cruz-Garcia and Price 2014:78-79).

Nature-culture dichotomy has been an important subject in anthropology for quite a long time (Ellen and Fukui 1996, Descola and Pálsson 1996), while perception and categorization of (wild) nature in science and modern society has lately been an actively disputed subject in ecosemiotics (e.g. Kull 1998, Maran 2004, 2006, Maran et al 2012, Augustyn 2013, Siewers 2014). Estonian semiotician Timo Maran argues that in small Finno-Ugric nation like Estonians, some concepts, among those 'wilderness' and 'culture-nature' opposition, are not operational (Maran 2014:79). He states:

Our cultural environment, historical legacy and experience of nature are rather different when compared with these in, for example, United States. Maybe the greatest difference between the so-called small and large cultures, and between the paradigms stemming from these cultures, is aiming at different degrees of generalisation. While in large culture, and a large scientific tradition deriving from such a culture, can quite naturally claim to represent universal experience and knowledge, the academic thinking of a small nation is haunted by the doubt whether the acquired knowledge represents only local matters of whether it is universally relevant (Maran 2014:79-80, italic added).

In this passage the differentiation on the lay - specialist/scholarly scale is rather problematic, although from the context we can assume that Maran is talking about scientific theoretical framework. However, the main argument seems to be that small culture perceives its nature in different ways from the way a large culture does, has more hesitations regarding the categorization and less need for it. We certainly cannot get comparative data, as an emic concept of a wild edible plant may be difficult if not impossible to frame for any specific larger nation, as modern nations (including US) are comprised of many small ethnical or regional groups.

Assuming that such emic concept does not, in fact, exist among Estonians (as it has not been established in scholarly thinking of Estonians), we can try to understand how people interpret (what keyword relate to) such a culturally abstract concept as a wild edible plant and how it corresponds with the etic, researchoriented concept.

The need for understanding the emic concept is especially urgent when the research subjects need to answer self-managed questionnaire and/or need to determine the domain of wild edible plants. If and in which respect does the scientific perception of 'wild food plants' overlap with the perception of lay people? Is it possible to trust a person to fill out a self-managed questionnaire addressing the use of wild plants - will we get 'wild' food plants in return? In fact, 
we will, at least it seemed that people with advanced botanical education rather intuitively grasped the meaning of 'wild edible plants' we asked them to list (Kalle and Sõukand 2013).

We also strive to detect the prototypes for the category of wild edible plants and see the reference points for describing the concept of wild plants among lay people in Estonia. This paper is a continuation of our research on the perception of nature and use of medicinal and wild edible plants in Estonia.

\section{Cultural and ecological background}

Estonia is situated in north-eastern part of Europe, bordering with Russia, Latvia and through the sea with Finland, covering 45 thousand $\mathrm{km}^{2}$. Its vegetation belongs to hemiboreal Baltic sub region of boreal European geobotanical region and this small territory can be divided into 12 plant-geographical regions (Lippmaa 1935). The vegetation of Estonia is well studied and documented since 1777, a detailed atlas of the distribution of vascular plants, using a 9x11 km grid, has recently been published (Kukk and Kull 2005). The number of known native and naturalized vascular plant species (with micro-species) of Estonia is estimated at 2200 (Kukk 1999, Ööpik 2008). Since the second half of the 20th century, intensive agriculture, collectivisation and urbanisation have caused many local species to diminish or even disappear (Kukk and Kull 2006). Meadows and grasslands constitute up to one-fifth (Peterson 1994), almost half of the territory is covered with forests, including almost one-third covered with peaty soils (Valk 1988). Hence, Estonians consider themselves a 'forest nation', closely attached to the local nature and able to utilize its resources. Indeed, a high proportion of local wild vegetation has been historically utilized and largely was still in use at the end of the 20th century as medicine and/or food (Sõukand and Kalle 2011, 2012a, 2012b, 2013, Kalle and Sõukand 2012, 2013).

The population of present-day Estonia counts to approximately 1.3 million inhabitants, $69 \%$ of them are Estonian-speaking (PHC 2011). Estonia has been considered a country with a high-income economy since 2006 (Word Bank...), although independence from the Soviet Union was obtained only in 1991, hence the need for wild food in the present society is marginal. However, some groups promoting eco-friendly lifestyle are dedicated users of local resources and as the majority of the population still has at least seasonal interaction with the countryside, the actual touch of nature still exists in everyday life of Estonians. Older generations still remember massive use of wild fruits, when, partly due to the low costs of sugar, all possible edible wild berries were preserved for winter, but also food shortages or even times of hunger. For example at the turn of 1990, before and after the collapse of the Soviet Union, access to food through retail was limited, as counters were half-empty and many food supplies were only available on ration cards. The hardest period, still vivid in the memories of the present population, was between 1940-1960, covering WWII and the post-war period. 
However, shortages of specific, especially fresh food were experienced to a smaller or greater extent throughout the entire Soviet period. This resulted in frequent utilization of wild food plants within this whole period. In addition to the need-induced use of local wild resources, many wild plants were and still are just snacked (Kalle and Sõukand 2013, Łuczaj et al. 2012), hence the 'taste of wild' should be familiar to the majority of the present adult generations.

\section{Data and methods}

In general, there are two major ways to determine what kinds of plants belong to a specific domain for specific person or some more or less limited group of people. One, the most easily and commonly used method to determine various conceptual categories, is to let a person simply free-list the items belonging to the category, in our case the wild (edible) plants. More complicated one, for a person, would be to ask to describe in few words what a 'wild plant' is. The latter, applied out of the context, may create a lot of confusion, if in everyday life there is no need to give sense to such concept. By combining both ways we can get two mutually complementing answers, which could give more reasonable results.

However, as in our case such combination happened literally by accident, without previous intention for a combination of two self-controlling methods. In 2011-2012 we conducted a research on the use of wild edible plants in Estonia in the childhood of the respondents. Electronic and/or printed questionnaires were distributed through numerous subject-list-serves, interest groups and even in one school. The questionnaire asked to list the uses of wild edible plants encountered in the childhood and to provide answers to few additional questions (for detailed methodology, collecting, plant identification, ethical issues, English translation of the questionnaire and also limitations of the this study please see Kalle and Sõukand 2013, Sõukand and Kalle 2013, Sõukand 2014).

As there is no specific word to describe the concept of wild edible plant in Estonian, the respondents were asked to list plants belonging to a category, which could be described using two partly overlapping phrases: looduslik taim (natural plant) and metsikult kasvav taim (plant that grows wild). In addition, a question addressing the concept was asked at the end of the questionnaire: "what was considered looduslik taim in your childhood?" (hereafter: categorization question).

From all responses received, only the 112 responses provided electronically by adults without advanced education in biology were pre-selected for present analysis. Of them $85(76 \%)$ answered the categorization question. The choice of non-specialists answers was guided by the need to get responses to the categorization question that were least affected by biological education and electronic answers were chosen as all those who answered electronically received feedback, follow-up questions and the possibility to update their list.

Although the received data was not obtained through the classical free-listing, when the list of the objects is composed ad-hoc, within the limited set of time 
(Quinlan 2005), all the respondents were given similar answering conditions. As all responses were provided in form of a table, they were easily converted into an excel database, use-reports (Tardío and Pardo de Santayana 2008) were not divided into detailed use reports in order to avoid too much confusion, as it was important that the taxa was used, and not how intensively it was used. For each taxon we calculated the cognitive salience index (Sal; Sutrop 2001), Sal shows the psychological salience through combining the frequency and mean position of a term used by the freelisting persons. It is obtained by dividing the frequency of mentioning of the specific taxa $(\mathrm{F})$ by number of all respondents $(\mathrm{N})$ and the mean position of the term in all the lists $(\mathrm{S}=\mathrm{F} /(\mathrm{N} \mathrm{mP}))$. In calculating salience index, only taxa listed in the very first response were taken into account, while later (after the follow-up questions) taxa were analysed separately.

For qualitative analysis, all selected answers were entered into RQDA software (Huang 2010). A code list was developed based on the keywords and emphasis the respondents used. In most of the cases one response was attributed several codes, as in one sentence several statements were presented. Codes were future categorized and selected code categories plotted in order to understand the main reference points for conceptualization of wild (food) plants.

\section{Results and discussion}

\subsection{Prototypes of looduslik toidutaim}

Every conceptual category must have one or more prototypes. "Prototypes with their rich non-criterial information and imagery can indicate, on many different levels, possible ways of situating oneself and navigating in complex situations" (Rosch 1999). Even if the concept of wild (edible) plants is not explicitly spelled out within the culture, the listing of species requested in the questionnaire must not be arbitrary. The selected 85 respondents listed the use of 163 different vascular plant taxa (and one lichen) in 1508 use reports. Of them 61 taxa were listed only once and 50 taxa were listed 2-5 times. Only 38 taxa were listed by more than 10 respondents. As importance of the taxa depends not only on its presence, but on its relative position in the list, we selected the most important taxa based on the salience index; the baseline was set on 0,01 (Table 1). Although in general the positions of prototypes of wild edible plants are more or less similar based on both, the salience index and frequency of citations, one plant (Rosa vosagiaca) has been listed only once, but named first.

It is rather difficult to tell, where to draw the borderline for prototypes of wild edible plants, hence we decided to use the salience index above 0.06 as the baseline. The first seven most popular taxa fit the scale based on both the salience index and the frequency of citations. However, one taxon, Oxalis acetosella, common childhood snacks for all generations of Estonians who had at least one 'forest experience', has undoubtedly the leading position. In recent years, however, Oxalis acetosella had been publicly (in popular books and media) advertised as slightly poisonous, hence its consumption is decreasing. Rumex acetosa, known 
Table 1. Most popular wild edible taxa and their salience index (Sal), the rank according to salience index (RankSal), the frequency of mentioning in the initial list $(F, n=85)$ and rank according to mentioning frequency (RankF). Habitat indicates the place where the species grow without direct cultivation by humans

\begin{tabular}{|c|c|c|c|c|c|}
\hline Taxa & Sal & RankSal & $\mathrm{F}$ & RankF & Habitat \\
\hline Oxalis acetosella L. & 0.193 & 1 & 78 & 1 & forest \\
\hline Rumex acetosa $\mathrm{L}$. & 0.12 & 2 & 51 & 7 & meadow \\
\hline Fragaria vesca L. & 0.108 & 3 & 70 & 2 & meadow/forest \\
\hline Vaccinium myrtillus L. & 0.095 & 4 & 63 & 3 & forest \\
\hline Rubus idaeus L. & 0.067 & 5 & 59 & 4 & forest \\
\hline Vaccinium vitis-idaea $\mathrm{L}$. & 0.066 & 6 & 56 & 6 & forest \\
\hline Vaccinium oxycoccos L. & 0.06 & 7 & 58 & 5 & bog/swamp \\
\hline Picea abies (L.) H.Karst. & 0.051 & 8 & 39 & 10 & forest \\
\hline Taraxacum officinale F.H.Wigg. s.l. & 0.049 & 9 & 40 & 8 & garden/meadow \\
\hline Lamium album $\mathrm{L}$. & 0.045 & 10 & 35 & 14 & garden/meadow \\
\hline Tilia cordata Mill. & 0.042 & 11 & 40 & 9 & bog \\
\hline Rubus chamaemorus L. & 0.041 & 12 & 38 & 11 & forest \\
\hline Primula veris $\mathrm{L}$. & 0.039 & 13 & 35 & 15 & meadow \\
\hline Urtica dioica $\mathrm{L}$. & 0.037 & 14 & 30 & 17 & garden/forest \\
\hline Sorbus aucuparia L. & 0.034 & 15 & 38 & 12 & forest/garden \\
\hline Vaccinium uliginosum $\mathrm{L}$. & 0.033 & 16 & 35 & 16 & forest \\
\hline Betula spp & 0.031 & 17 & 30 & 18 & forest/garden \\
\hline Corylus avellana $\mathrm{L}$. & 0.03 & 18 & 37 & 13 & forest \\
\hline Rumex spp & 0.03 & 19 & 17 & 28 & meadow \\
\hline Prunus padus L. & 0.025 & 20 & 27 & 19 & garden/forest \\
\hline Carum carvi $\mathrm{L}$. & 0.025 & 21 & 27 & 20 & meadow/garden edge \\
\hline Rosa spp & 0.023 & 22 & 25 & 22 & forest \\
\hline Aegopodium podagraria L. & 0.021 & 23 & 17 & 29 & garden \\
\hline Juniperus communis L. & 0.021 & 24 & 26 & 21 & meadow \\
\hline Pinus sylvestris L. & 0.02 & 25 & 18 & 27 & forest \\
\hline Acer platanoides L. & 0.02 & 26 & 23 & 23 & garden/forest \\
\hline Achillea millefolium $\mathrm{L}$. & 0.017 & 27 & 21 & 24 & meadow \\
\hline Fragaria viridis Duchesne & 0.017 & 28 & 21 & 25 & meadow \\
\hline Rubus caesius L. & 0.017 & 29 & 19 & 26 & forest/meadow \\
\hline Poaceae & 0.014 & 30 & 16 & 30 & meadow \\
\hline Phleum spp & 0.014 & 31 & 14 & 31 & meadow \\
\hline Syringa vulgaris L. & 0.012 & 32 & 13 & 32 & garden \\
\hline Rosa vosagiaca N.H.F.Desp. & 0.012 & 33 & 1 & $104-164$ & forest \\
\hline Berberis vulgaris L. & 0.01 & 34 & 12 & 34 & park \\
\hline Origanum vulgare $\mathrm{L}$. & 0.01 & 35 & 13 & 33 & meadow \\
\hline
\end{tabular}

as snack, but also a component of the traditional sorrel soup, was second based on the salience index, but only seventh based on the frequency of citations; also, quite a few respondents recalled the use of domesticated, not wild sorrel. Although those two green snacks are perceived as most characteristic 'wild edible plants', the rest of the taxa presented at the top of the list are the so-called berries (marjad), all fruits growing in the forest (except Fragaria vesca that, in addition to forest, grows also on the edges of forest, meadows and wooden meadows); Vaccinium oxycoccos, grows in bogs and swamps, which can, on the popular level, 
be also considered as 'forest' if there is not explicit need for specification. However, this reflects only the 'wild edible plants' prototypes for the time settings covered in the study (the second half of the 20th century), and it was most probably the peak of the use of wild fruits (Kalle and Sõukand 2013).

The low salience index even in the case of most popular wild edible plants, signals great personal variations in what order people recall the use or perceive the importance of specific wild edibles. Indeed, there were 28 species listed by at least two respondents among the first three taxa in the initial list (Table 2). We can possibly assume that the species listed first were the ones that occurred to a person first (i.e. they associate most strongly with the perception of what a wild edible plant should be) or alternatively, if the person pre-structured the list before filling it out electronically, those that he or she deemed the most important in such domain. Such a great variety among the most shortlisted species affirms variations of personal perception of prototypes of wild edible species.

Table 2. The frequency of mentioning the species in the first three positions in the initial lists. Included are only species mentioned among first tree species by at least two respondents

\begin{tabular}{|c|c|c|c|c|}
\hline \multirow[t]{2}{*}{ Taxa } & \multicolumn{3}{|c|}{ Position in the list } & \multirow[t]{2}{*}{ SUM } \\
\hline & 1 & 2 & 3 & \\
\hline Oxalis acetosella L. & 26 & 17 & 5 & 48 \\
\hline Rumex acetosa L. & 12 & 12 & 5 & 29 \\
\hline Fragaria vesca L. & 7 & 6 & 8 & 21 \\
\hline Vaccinium myrtillus L. & 2 & 4 & 11 & 17 \\
\hline Taraxacum officinale F.H.Wigg. s.l. & 3 & 4 & 3 & 10 \\
\hline Picea abies (L.) H.Karst. & 1 & 2 & 7 & 10 \\
\hline Tilia cordata Mill. & 7 & & 2 & 9 \\
\hline Rumex spp. & 6 & 2 & & 8 \\
\hline Rubus idaeus $\mathrm{L}$. & & 5 & 3 & 8 \\
\hline Primula veris $\mathrm{L}$. & 1 & 3 & 3 & 7 \\
\hline Lamium album $\mathrm{L}$. & 3 & & 4 & 7 \\
\hline Betula spp. & 3 & 2 & 2 & 7 \\
\hline Urtica dioica $\mathrm{L}$. & 1 & 1 & 2 & 4 \\
\hline Rubus chamaemorus L. & & 2 & 2 & 4 \\
\hline Rosa spp. & 1 & 1 & 2 & 4 \\
\hline Allium ursinum $\mathrm{L}$. & 1 & 3 & & 4 \\
\hline Sorbus aucuparia L. & & 1 & 2 & 3 \\
\hline Vaccinium oxycoccos L. & 1 & 1 & 1 & 3 \\
\hline Aegopodium podagraria $\mathrm{L}$. & & 1 & 2 & 3 \\
\hline Vaccinium uliginosum $\mathrm{L}$. & 1 & & 1 & 2 \\
\hline Tragopogon pratensis $\mathrm{L}$. & & 1 & 1 & 2 \\
\hline Prunus padus L. & & 1 & 1 & 2 \\
\hline Poaceae & & 2 & & 2 \\
\hline Pinus sylvestris L. & 1 & & 1 & 2 \\
\hline Mentha $\times$ piperita $\mathrm{L}$. & & & 2 & 2 \\
\hline Corylus avellana $\mathrm{L}$. & 1 & & 1 & 2 \\
\hline Carum carvi $\mathrm{L}$. & & 2 & & 2 \\
\hline Acer platanoides L. & & 2 & & 2 \\
\hline
\end{tabular}




\subsection{Forgotten wild food plants}

As there was no time limit set for answering the questionnaire, only the respondent's knowledge, experience, memory and personal time-limit guided the response. However, many respondents updated their responses after our later correspondence. The idea of the correspondence was to thank the respondents and provide general feedback to their response, but also to ask some additional questions, driven from the specific response and from particular research interest.

Responding to the follow-up questions, only 48 respondents of 85 provided 373 additional use reports. 35 of them were related to cultivated plants (classified as such by both researchers and respondents) which were cultivated for food. The most common of them (three or more reports) were Ribes nigrum L., Rheum rhaponticum L., Malus domestica Borkh. and Allium sativum L.). 81 use reports were describing medicinal use only. The remaining 243 use reports were submitted by 40 respondents and contained 88 taxa. Of them 18 species were mentioned by five or more respondents (Table 3 ).

In general, quite a large proportion of added taxa were related to plants used for making recreational tea (like Tilia cordata) and spices (like Carum carvi) as the respondents were explicitly asked for those (Sõukand and Kalle 2013). Also, among them were many forest berries, as several respondents listed them first as a group, considering the use of berries quite ordinary and obvious and probably not interesting for us as researchers. One group of plants listed after follow-up were plants cultivated for non-food purposes (like Syringa vulgaris) or those that were not actually considered wild by many respondents (like naturalized Armoracia rusticana). However, a large proportion of the plants was simply forgotten during the first response, either because they had been consumed just once (mainly tasted only, like Quercus robur) or were such obvious children snacks as Primula veris. In addition, several respondents at first forgot to mention sap trees as they were not sure it can be considered wild food.

\subsection{Mapping the concept}

The list of the most salient and most frequently listed plants and as a contrast of the plants in the updated list provide us with some of the ideas of folk perception of wild edible plants, but it barely gives us information on how people conceptualize the 'wild plant'. More detailed insights are gained from the analysis of written responses to the specific conceptualization question. However, regardless the context of edible plants, the conceptualizing question was directed toward general perception of wild plants, hence it must be kept in mind while reading the following.

Although all the respondents who addressed the question tried to explain the 'wild plant' through certain keywords, the existence of the concept in one's childhood was in a few cases (by five respondents) doubted. Just one quite specific example: 
Probably everything that was growing in the open nature, which was not growing in the garden and farmland. But $I$ am not sure if $I$ investigated this question at all. [Female, b. 1969, grew up in town]

Table 3. List of plant taxa most commonly added after the follow-up correspondence

\begin{tabular}{|c|c|c|c|c|}
\hline Taxa & $\begin{array}{l}\text { Follow-up } \\
\text { UR }(\mathrm{n}=40)\end{array}$ & $\begin{array}{c}\text { Initial UR } \\
(\mathrm{n}=85)\end{array}$ & Habitat & $\begin{array}{l}\text { Possible reasons for exclusion from } \\
\text { initial free-list }\end{array}$ \\
\hline Betula spp & 18 & 30 & $\begin{array}{l}\text { Forest, } \\
\text { garden }\end{array}$ & $\begin{array}{l}\text { The 'part of the plant' consumed is } \\
\text { mostly sap, hence it did not occur to } \\
\text { people to list its use or was not } \\
\text { considered wild, if the trees used grew in } \\
\text { the home yard }\end{array}$ \\
\hline $\begin{array}{l}\text { Fragaria vesca } \\
\text { L. }\end{array}$ & 8 & 70 & $\begin{array}{l}\text { Forest, } \\
\text { meadow }\end{array}$ & $\begin{array}{l}\text { The use of berries is a kind of common } \\
\text { knowledge and people often did not even } \\
\text { think of it or named generally 'all kinds } \\
\text { of forest berries' }\end{array}$ \\
\hline $\begin{array}{l}\text { Tilia cordata } \\
\text { Mill. }\end{array}$ & 8 & 40 & Garden, park & $\begin{array}{l}\text { Plants used for making recreational tea } \\
\text { were the special focus of the follow-up }\end{array}$ \\
\hline $\begin{array}{l}\text { Vaccinium vitis- } \\
\text { idaea } \mathrm{L} \text {. }\end{array}$ & 6 & 56 & Forest & See Fragaria vesca \\
\hline $\begin{array}{l}\text { Syringa vulgaris } \\
\text { L. }\end{array}$ & 6 & 13 & Forest & $\begin{array}{l}\text { Little details, as eating 'lucky' flowers, is } \\
\text { easy to forget }\end{array}$ \\
\hline Rubus idaeus L. & 6 & 59 & Forest & See Fragaria vesca \\
\hline $\begin{array}{l}\text { Armoracia } \\
\text { rusticana Gaertn. } \\
\text { et al. }\end{array}$ & 6 & 2 & Garden & $\begin{array}{l}\text { Was not considered 'wild' or was used as } \\
\text { spices for lactofermented cucumbers, so } \\
\text { forgotten in first list }\end{array}$ \\
\hline $\begin{array}{l}\text { Oxycoccus } \\
\text { palustris Pers. }\end{array}$ & 5 & 58 & Bog/swamp & See Fragaria vesca \\
\hline Primula veris $\mathrm{L}$. & 5 & 35 & Meadow & Simply forgotten \\
\hline Quercus robur $\mathrm{L}$. & 5 & 11 & $\begin{array}{l}\text { Park, } \\
\text { meadow, } \\
\text { forest }\end{array}$ & $\begin{array}{l}\text { Rather minor use (just tasting), so it did } \\
\text { not immediately occur to people }\end{array}$ \\
\hline Carum carvi $\mathrm{L}$. & 5 & 27 & $\begin{array}{l}\text { Meadow/gar } \\
\text { den edge }\end{array}$ & $\begin{array}{l}\text { Did not come on mind as something } \\
\text { eaten, as used mainly as tea and spice }\end{array}$ \\
\hline $\begin{array}{l}\text { Rubus } \\
\text { chamaemorus L. }\end{array}$ & 5 & 38 & $\begin{array}{l}\text { Meadow, } \\
\text { forest }\end{array}$ & See Fragaria vesca \\
\hline Urtica dioica $\mathrm{L}$. & 5 & 30 & $\begin{array}{l}\text { Garden, } \\
\text { meadow, } \\
\text { edges }\end{array}$ & Simply forgotten \\
\hline $\begin{array}{l}\text { Vaccinium } \\
\text { uliginosum } \mathrm{L} .\end{array}$ & 5 & 35 & Forest & See Fragaria vesca \\
\hline $\begin{array}{l}\text { Sorbus } \\
\text { aucuparia } \mathrm{L} \text {. }\end{array}$ & 5 & 38 & $\begin{array}{l}\text { Forest, } \\
\text { garden }\end{array}$ & $\begin{array}{l}\text { Was considered a 'forest berry' as } \\
\text { Fragaria vesca }\end{array}$ \\
\hline $\begin{array}{l}\text { Acer platanoides } \\
\text { L. }\end{array}$ & 5 & 23 & $\begin{array}{l}\text { Forest, } \\
\text { garden }\end{array}$ & See Betula spp. \\
\hline $\begin{array}{l}\text { Vaccinium } \\
\text { myrtillus L. }\end{array}$ & 5 & 63 & Forest & See Fragaria vesca \\
\hline
\end{tabular}


Only three persons described the concept as something changing over the time, although it might be true for many respondents. One respondent, who provided 19 taxa in the first response and added three taxa later, described her perceptions through the specific places of her childhood:

Around my childhood country house in Karjametsa farm [looduslik taim was for me] everything that was growing outside my grandma's garden and for which grandma was not taking care of, e.g. was not weeding, was not protecting with net against birds, did not cut branches. Beyond the country house it was all that grew in the forest, road-side or else on the territory not surrounded by fence or not marked otherwise.

At first, parents told from where I can take plants, later I learned this myself.

During the elementary school years in Tallinn in Rahumäe, the 'looduslik taim' were all those plants, which were growing outside someone's garden, including Rahumäe graveyard.

When I was living in Tartu in Nooruse dormitory [as a university student], I picked apples that had fallen down, even if the tree was growing in someone's garden. I did the same also in Tallinn in Lilleküla and Rahumäe-Nõmme, the owners of the trees have not minded, particularly when in the years when apples are in abundance. [Female, b. 1975, grew up in the village and the city]

Such keywords as 'not surrounded by fence' (coded for regimenting jointly with 'not at home') and 'grandma was not taken care of' (coded as 'not cared for') signal that the ownership of the land and the grower of the plant play an important role in defining if the plant is wild or not, although this applies to few responses only. The whole theme of the ownership contained 3 codes that referred to the land or the plants as belonging to someone-our, grandparents', other people.

\subsection{Rare codes}

While coding, the idea was to retain the code as close as possible to the original keywords and intentions used by the respondent, to map the most exact emic perception of the concept. While it was important to create as few codes as possible, trying to minimize the number of codes having only one corresponding text, there were seven such codes attributed to one and three codes attributed to two texts. Those were retained to cover important features of the concept not covered by other codes. To provide some examples:

"I considered looduslik all those plants that were growing independently (without human care or not being cultivated by humans) in forest, bog, water or meadow." [Female, b. 1971, grew up in city and village.]

Although historically and according to the responses to this questionnaire, several water plants were actually consumed, only one person mentioning water as the medium of their growth is a bit surprising. Moreover, among 37 taxa mentioned by this particular respondent, none was growing in the water.

All that grew in nature, including around old houses. [Male, b 1982, grew up in village] 
After the deportation of people to Siberian prison camps and collectivisation of the 1940s and later on, many farm buildings were left unattended and eventually fell into ruin all across Estonian countryside, hence the gathering of plants around such places was rather common. However, the respondent, who mentioned the use of 31 plants, named only one species which potentially could be found in (abandoned) garden only (Scilla siberica Haw.) and mentions two more (Ribes nigrum L. and Armoracia rusticana Gaertn. et al.) on the future request.

"Looduslikud taimed were those, which were not mad of plastic and those that were growing outside garden." [Female, b. 1989, grew up in the village]

However anecdotic plants not made of plastic may sound, this in fact represents the opinion of younger generation not very familiar with the natural surroundings. There were only 10 species in her response, including two species that she later categorized as cultivated.

\subsection{Major themes}

In order to identify other possible thematic divisions, all 35 codes (including the frequently mentioned ones) were divided into several, mutually overlapping categories to map the themes associated with the categorization of wild. Figure 1 contains the relations between codes covered by the first four general themes, covering 30 codes (two conceptualization codes - no concept and changing concept, and three ownership codes did not fit those categories).

Inclusion contained 21 codes that emphasize inclusion of the feature 'looduslik taim' into some class - like forest, all, nature. Abundant in codes, although many of them occur in only one-two texts, the inclusion seems to be one of the main characteristics of the intention of describing a wild plant, relating it to some other known category or place of growth of the plant. Almost $80 \%$ of the respondents used inclusions to some extent in their responses.

Exclusion contained 9 codes that claim that the feature does not belong into some specific class - e.g. not cultivated, not weeded, not plastic, through which almost $70 \%$ of the respondents expressed part of their thoughts. Opposing a 'wild plant' to something more familiar and most probably more used, indicating that everything not belonging to another specific class belongs to the requested category.

Generalization contained 16 codes that refer to the higher level of generalization - e.g. all, nature, grows itself, being the greatest covered theme. Although many respondents in the same responses are also very specific about the places, over $90 \%$ or the respondents added some generalization remark, indicating that a 'wild plant', if conceptualized, is something that cannot be simply outlined.

Specification contained 12 codes that belong to specific class - e.g. forest, weed, park, specific species, etc. This category of codes contains the greatest number of codes attributed to only one or a few texts, and less than $50 \%$ of the respondents really were specific when addressing the concept of wild plants. 


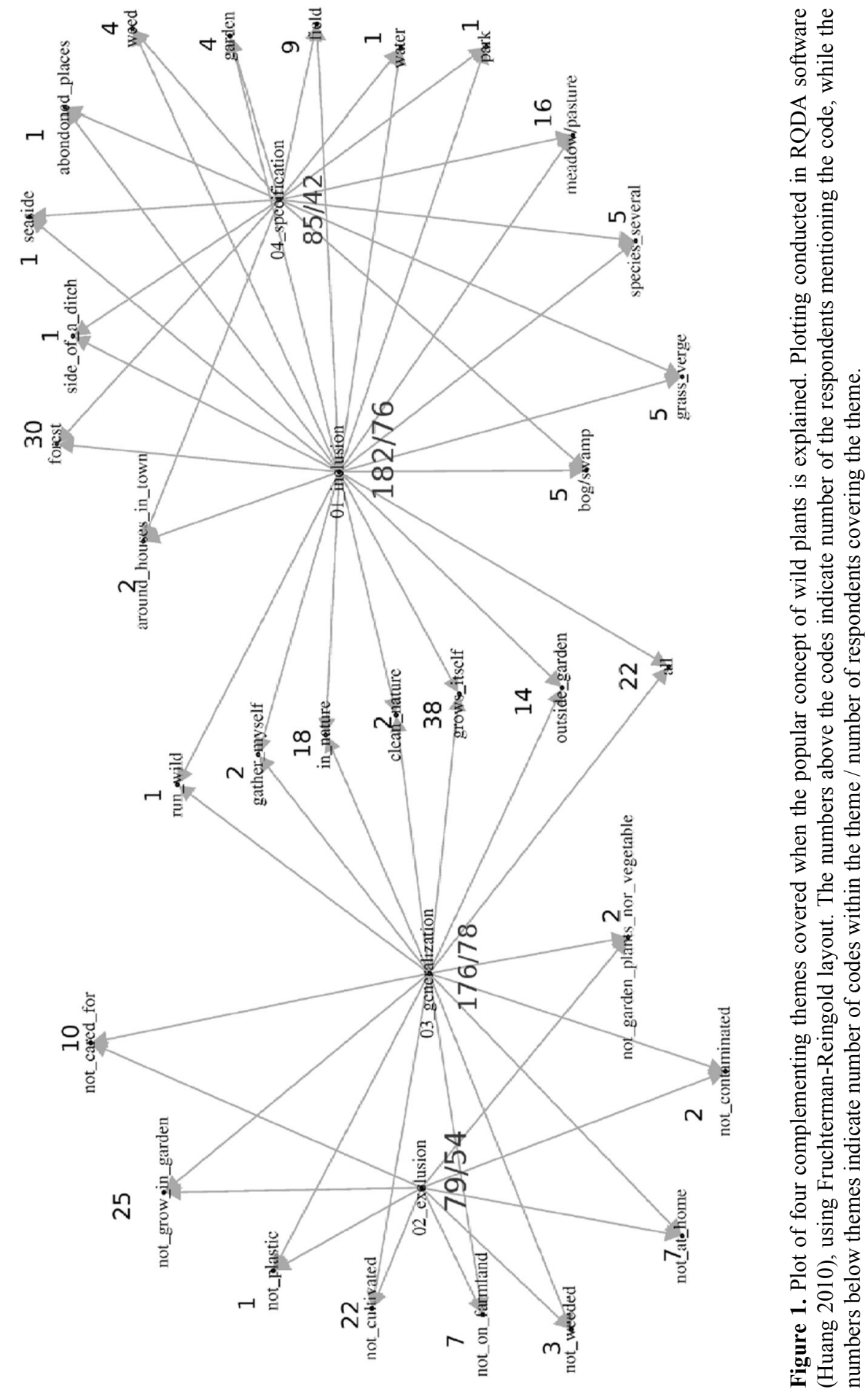


In addition to four listed, theme indicating the habitat can be identified. It contained 12 codes that refer to growing in specific places - e.g. garden, not in the garden, water, forest, meadow/pasture, bog/swamp, park, abandoned places, not on farmland but also 4 edge-related codes (grass verge, side of the ditch or around houses in towns, seaside) which have traditionally been also well exploited as places for gathering wild food plants, as species richness there is regularly higher. Slightly over $70 \%$ of the respondents were specifying the habitat of the 'wild plant' that in turn, shows quite a good understanding of where such plants could be found.

\subsection{Reference points}

Ten most popular codes (attributed to keywords mentioned by at least 10\% of the respondents) deserve closer attention and analysis. Those expose the most common reference points people used to describe the concept of wild plants. We grouped them in four little groups that in our opinion represent the core foundation of the concept at the given time and cultural settings.

The ability to grow itself is expressed through two opposing codes grows itself (30 responses) - not grow in the garden ( 25 responses). 'Grows itself' was sometimes worded more simply 'grows', but the intention was the same. Garden plants, generally, do not have the ability to grow themselves, hence the opposition to the plants that grow in the garden.

'Looduslik taim' was the one that 'grew itself', e.g. there was no need to plant

it or take care of it. [Male, b. 1973, grew up in town and the village]

Plants that were growing in forest or nature, not the garden plants. [Female,

b. 1964, grew up in the city]

Through the inclusion of all 'grows' into the 'grow itself' code, it became the most numerously attributed code. It is rather close to 'birth itself' expression related to the wildness of a plant in Thailand, as explained by Cruz-Garcia and Price (2011), although 'growing' only starts from regenerating. Stressing the ability of the plat to grow independently or 'on its own', provides one of the main conceptualization reference points.

Opposition to cultivation is expressed by two mutually complementing codes not cultivated (22 responses) - not cared for ( 9 responses), both opposing independent growth. "Not cultivation" indicates that a plant is not seeded, planted, or otherwise supported:

All that grew in nature and was not planted vegetables and what did not need weeding during the endless days. [Male, b. 1975, grew up in the village]

All that, to my knowledge, was not knowingly cultivated and that grew outside home garden or was so called 'weed'. [Female, b. 1974, grew up in the village]

'Caring for' can also be seen, although not explicitly shown in our context, as a mean of manipulation of wild species as well (compare with Turner et al. 2011). 
Place of growth: forest (30) - meadow/pasture (16) - farmland (9)

Although such code as not on farmland also existed, the idea of the code farmland is to show that many wild plants grew, in the respondents' opinion, on cultivated land, although the land was not cultivated for them.

All that was not growing on headland but grew on meadow, in the field or next to the headland. Not on farmland. Rather in the field, on hayfield and in forest. [Female, b. 1942, grew up in the village]
Abstraction: outside the garden (14 responses) - all (22 responses) - in nature (18 responses)
Although seemingly outside the garden coincides with does not grow in the garden, the intention of the former is related to the inclusion of everything that grows outside specific area, while the latter reflects the opposition to what is growing in a specific place (garden). As well as all and in nature, abstractions reflect a very vague and general understanding of what could belong to the category of 'wild plant'.

All the plants that grew in nature and were eaten. [Female, b. 1968, grew up in the village]

All plants that grew on their own. [Female, b. 1956, grew up in the village]

\section{Does the category of wild plants exist in folk cognition?}

While the categorization question addressed wild plants as such, not specifically wild edible plants, the context of the question (preceding list of plants eaten in childhood) conditioned, at least to a certain extent, the relation of this wild plant with its edibility. "Concepts are situation based and participatory rather than identification functions.... The entire background of practices, understandings and explicit teachings with which we have been raised come into play" (Rosch 1999). If, based on the received responses, we want to provide a general lay definition of looduslik taim, it would sound like:

all the plants that are not cultivated (cared for) by humans, hence grow outside the garden (home).

The conceptual frame of a wild plant is rooted on the opposition to cultivation, embracing all that stays beyond the human involvement process. "Concepts only exist against a non-conceptual background. We could not even think to talk about concepts and conceptualization without some contrast of what they are not" (Rosch 1999). Our respondents framed wild plant dominantly through the opposition to the known and operational concept such as culture (cultivation, caring for the plant), which is known and experienced by the majority of the respondents. The concept for 'wild plant' does not actually exist, but it is structured through several other concepts and categories, most explicitly expressed is the opposition to cultivation or other forms of human care/attendance, as "perceived world comes as structured information rather than as arbitrary or unpredictable attributes" (Rosch 1978). 
However, 'wild' or 'nature' is also experienced by all the respondents, as they specify their perception of what is a wild plant or where it could be found, and they list specific plant taxa (as long as edible plants are concerned). The culturenature opposition is provided mostly to create such conceptual definition, needed only to answer the researcher's question. In fact, the majority of the respondents combined opposition with inclusion and/or specification with the generalization. The distribution of keywords that people used to describe 'wild plant' suggests that generalization overweighs specification by almost three times, and this signals the vagueness of the concept. Still, the inclusion overweighs the exclusion almost twice and this signals that the respondents have quite a good understanding of what plants are actually wild and where to find them.

Categorization has been one of the basic functions of human beings, as it allows "to treat distinguishable objects and events as equivalent" (Rosch 1999). However, in the case of wild plants, historically there seemed no need to treat all wildly growing plants as equivalent, as they bear different functions according to which different categories were created: medicine, food, dye, handicraft, building and fire material, and the rest - recognizable and differentiated, but categorized under general heading hein (hey) or rohi (grass) or puud (trees) or võsa (underwood). While the category of "edible (or food) plants" (toidutaimed, söögitaimed) existed, it was not differentiated on wild-cultivated level (Kalle and Sõukand 2011). The reason for that may lay in fact that 'gardening culture' developed in Estonia only in the 1920s. Estonians were de jure serfs until the 1820s, but it was only at the end of the 19th century when they were allowed to buy land. Until that time, there was no reason to create a garden, as landlord could re-locate his peasants very quickly and rent out the lucrative property to someone else. Gardens, as well as parks existed in every manor, run by landlords and taken care of by peasants, but they were not perceived as 'own'. However, when at the beginning of the 20th century the garden culture started to flourish, there gradually appeared the need to differentiate cultivated plants, while the rest (wild plants) constituted a solid background that did not need explicit categorization. This may have changed (or will eventually change) in the 21 st century, as the use of wild plants in modern Estonia is not that obvious as it was at the end of the 20th century, containing more elements of neoteric or re-introduced traditional knowledge, both learned from books and media as the traditional ways of learning had been abandoned in urbanized society, where different generations no longer live together and the time children spend behind the computers increases while time spent outdoors decreases.

\section{Conclusion}

In the Estonian realm of the second half of the 20th century there was no need for conceptualization of wild (edible) plants. However, people could describe quite convincingly what they think wild edible plants should be. Even if every single 
person did not define 'wild (edible) plants' the same way as scholarly writings do, the general understanding of what should be a wild edible plant largely coincided with what is agreed upon in ethobotany as science, at least in Estonia during the given time span.

As concepts wary in time and space, the understanding of what 'wild plant' is may be different elsewhere or even in modern Estonia. Hence, for the future research, it would be important to understand what affects the formation of the concept and how it influences attitudes toward perception and the use of species considered wild, but also the transfer of the knowledge related to wild plants.

\section{Acknowledgments}

The research has been supported by ESF grants IUT 22-5 and ETF9419. Many thanks to all our inspiring correspondents, and to colleagues Timo Maran and Monika Kujawska for constructive comments and suggested references.

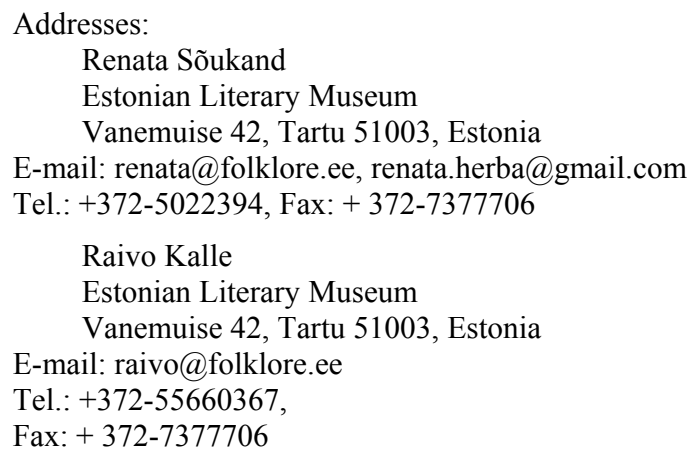

\section{References}

Augustyn, Prisca (2013) "Man, nature, and semiotic modelling or How to create forests and backyards with language“. Sign Systems Studies 4, 488-503.

Ellen, Roy F. and Katsuyoshi Fukui, eds. (1996) Redefining nature: ecology, culture, and domestication. Oxford: Berg.

Etkin, Nina L. (1994) Eating on the wild side: the pharmacologic, ecologic, and social implications of using noncultigens. Tucson, AZ: University of Arizona Press.

Etkin, Nina L. (2006) Edible medicines: an ethnopharmacology of foods. Tucson, AZ: University of Arizona Press.

Cruz-Garcia, Gisella S. and Lisa. L. Price (2011) "Ethnobotanical investigation of 'wild' food plants used by rice farmers in Kalasin, Northeast Thailand". Journal of ethnobiology and ethnomedicine 7, 1, 33.

Cruz-Garcia, Gisella S. and Lisa L. Price (2014) "Human-induced movement of wild food plant biodiversity across farming systems is essential to ensure their availability". Journal of Ethnobiology 34, 1, 68-83. 
Dénes, Andera, Nora Papp, Daniel Babai, Bálint Czúcz, and Zsolt Molnár (2012) "Wild plants used for food by hungarian ethnic groups living in the Carpathian Basin". Acta Societatis Botanicorum Poloniae 81, 4, 381-396.

Descola, Philippe and Gísli Pálsson, eds. (1996) Nature and society: anthropological perspectives. Taylor and Francis.

Dufour, Darna L. and Warren M. Wilson (1994) "Characteristics of 'wild' plant foods used by indigenous populations in Amazonia". In Eating on the wild side: the pharmacologic, ecologic, and social implications of using noncultigens, 114-142. Nina L. Etkin, ed. Tucson, AZ: University of Arizona Press.

Huang, Ronggui (2010) RQDA: R-based qualitative data analysis. Available at $<$ http://rqda.r-forge.rproject.org/>. Accessed on 20 March 2014.

Kalle, Raivo and Renata Sõukand (2011) "Eestikeelsete rahvapäraste taimenimede kategoriseerimine ja selle rakendatavus tänapäeval". [Estonian vernacular plant names and the possibilities of modern use of categorization.] In Eesti teaduskeel ja terminikorrastus, 24-46. Peep Nemvalts, ed. [Estonian scientific language and regulation of terminology.]Tallinn: Tallinna Ülikool.

Kalle, Raivo and Renata Sõukand (2012) "Historical ethnobotanical review of wild edible plants of Estonia (1770s-1960s)”. Acta Societatis Botanicorum Poloniae 81, 4, 271-281.

Kalle, Raivo and Renata Sõukand (2013) "Wild plants eaten in childhood: retrospective of 1970s1990s Estonia". Botanical Journal of the Linnean Society 172, 239-253.

Kukk, Toomas (1999) Eesti taimestik. [Flora of Estonia] Tallinn: Teaduste Akadeemia Kirjastus.

Kukk, Toomas and Tiiu Kull, eds. (2005) Eesti taimede levikuatlas. Atlas of the Estonian Flora. Tartu: Eesti Maaülikool.

Kukk, Toomas and Tiiu Kull (2006) "Globaalne ja lokaalne eesti taimestik". [Global and local Estonian flora.] In Inderk Rohumets, ed. Lehed ja Tähed: Looduse ja Teaduse Aastaraamat, 10-17. [Leaves and stars. Yearbook of nature and science.] Tallinn: MTÜ Loodusajakiri.

Kull, Kalevi (1998) "Semiotic ecology: different natures in the semiosphere". Sign Systems Studies $26,1,344-371$

Lippmaa, Theodor (1935) “Eesti geobotaanika põhijooni. Aperçu géobotanique de l'Estonie”. Acta Instituti et Horti Botanici Universitatis Tartuensis, Vol. 4, fasc. 3-4. Tartu: K. Mattiesen.

Logan, Michael and Anna R. Dixon (1994) "Agriculture and the acquisition of medicinal plant knowledge". In Eating on the wild side: the pharmacologic, ecologic and social implications of using noncultigens, 25-45. Nina Etkin, ed. Tucson, AZ: University of Arizona Press.

Łuczaj, Łukasz (2012) "Ethnobotanical review of edible plants of Slovakia". Acta Societatis Botanicorum Poloniae 81, 4, 245-255.

Łuczaj, Łukasz (2008) "Archival data on wild food plants used in Poland in 1948". Journal of Ethnobiology and Ethnomedicine 4, 1, 4.

Łuczaj, Łukasz, Andrea Pieroni, Javier Tardío, Manuel Pardo-de-Santayana, Renata Sõukand, Ingvar Svanberg, and Raivo Kalle (2012) "Wild food plant use in 21st century Europe: the disappearance of old traditions and the search for new cuisines involving wild edibles". Acta Societatis Botanicorum Poloniae 81, 4, 359-370.

Łuczaj, Łukasz and Wojciech M. Szymański (2007) "Wild vascular plants gathered for consumption in the Polish countryside: a review". Journal of Ethnobiology and Ethnomedicine 3,17.

Maran, Timo (2014) "Place and sign. Locality as a foundational concept for ecosemiotics". In Reimagining nature: environmental humanities and ecosemiotics, 79-89. Alfred K. Siewers, ed. Lewisburg: Bucknell University Press.

Maran, Timo, Kati Lindström, Riin Magnus, and Morten Tønnessen, eds. (2012). Semiotics in the wild. Essays in Honour of Kalevi Kull on the occasion of His 60th birthday. Tartu: University of Tartu Press.

Maran, Timo (2006) "Where do your borders lie? Reflections on the semiotical ethics of nature". In Nature in Literary and Cultural Studies: Transatlantic Conversations on Ecocriticism 3, $455-476$.

Maran, Timo (2004) “Gardens and gardening: an ecosemiotic view”. Semiotica 150, 119-134. 
Menendez-Baceta, Gorka, Laura Aceituno-Mata, Javier Tardío, Victoria Reyes-García, and Manuel Pardo-de-Santayana (2012) "Wild edible plants traditionally gathered in Gorbeialdea (Biscay, Basque Country)." Genetic Resources and Crop Evolution 59, no. 7, 1329-1347.

Molina, María, Javier Tardío, Laura Aceituno-Mata, Ramón Morales, Victoria Reyes-García, and Manuel Pardo-de-Santayana (2014) "Weeds and food diversity: natural yield assessment and future alternatives for traditionally consumed wild vegetables". Journal of Ethnobiology 34, $1,44-67$.

Nebel, Sabine, Andrea Pieroni, and Michael Heinrich (2006) "Ta chòrta: wild edible greens used in the Graecanic area in Calabria, Southern Italy". Appetite 47, 3, 333-342.

Ööpik, Merle, Toomas Kukk, Kalevi Kull, and Tiiu Kull (2008) "The importance of human mediation in species establishment: analysis of the alien flora of Estonia". Boreal environment research 13: 53-67.

Peterson, K. (1994) Nature conservation in Estonia. Tallinn: Juma.

Pieroni, Andrea, Sabine Nebel, Rocco Franco Santoro, and Michael Heinrich (2005) "Food for two seasons: culinary uses of non-cultivated local vegetables and mushrooms in a south Italian village". International Journal of Food Sciences and Nutrition 56, 4, 245-272.

Pieroni, Andrea, V. Janiak, C. M. Dürr, S. Lüdeke, E. Trachsel, and Michael Heinrich (2002a) "In vitro antioxidant activity of non-cultivated vegetables of ethnic Albanians in southern Italy". Phytotherapy Research 16, 467-473.

Pieroni, Andrea, Sabine Nebel, Cassandra Quave, Harald Münz, and Michael Heinrich (2002b) "Ethnopharmacology of liakra: traditional weedy vegetables of the Arbëreshë of the Vulture area in southern Italy". Journal of Ethnopharmacology 81, 165-185.

Pieroni, Andrea, and Cassandra L. Quave (2006) "Functional foods or food medicines? On the consumption of wild plant among Albanians and Southern Italians in Lucania". In Eating and healing: traditional food as medicine, 101-129. Andrea Pieroni and Lisa Price, eds. New York, NY: Haworth Press.

PHC 2011: people of 192 ethnic nationalities live in Estonia http://www.stat.ee/ 64310?parent_id=39113. Accessed 20.10.2014.

Redžić, Sulejman (2006) "Wild edible plants and their traditional use in the human nutrition in Bosnia and Herzegovina". Ecology of Food and Nutrition 45, 189-232.

Redžić, Sulejman (2010) "Use of wild and semi-wild edible plants in nutrition and survival of people in 1430 days of siege of Sarajevo during the war in Bosnia and Herzegovina (1992-1995)". Collegium Antropologicum 34, 2, 551-570.

Rosch, Eleanor (1999) "Reclaiming concepts". In Reclaiming cognition: the primacy of action, intention and emotion. Rafael Núñez and Walter J. Freeman, eds. Thorverton, Eng.: Imprint Academic. Published simultaneously as a special issue of The Journal of Consciousness Studies 6, 11-12, 61-77.

Rosch, Eleanor (1978) "Principles of Categorization". In Cognition and categorization, 27-48. E. Rosch and B. B Loyd, eds. Hillsdale, NJ: Lawrence Erlbaum.

Quave, Cassandra L. and Andrea Pieroni (2014) "Fermented foods for food security and food sovereignty in the Balkans: a case study of the Gorani people of Northeastern Albania". Journal of Ethnobiology 34, 1, 28-43.

Quinlan, Marsha (2005) "Considerations for collecting freelists in the field: examples from ethobotany". Field Methods 17, 3, 219-234.

Sánchez-Mata, M. C., Cabrera-Loera, R. D., Morales, P., Fernández-Ruiz, V., Cámara, M., DíezMarqués, C., et al. (2012) "Wild vegetables of the Mediterranean Area as valuable sources of bioactive compounds". Genetic Resources and Crop Evolution 59, 431-443.

Siewers, Alfred Kentigern, ed. (2014) Re-imagining nature: environmental humanities and ecosemiotics. Lewisburg: Bucknell University Press.

Sõukand, Renata (2014) "What are the main criteria of science? Unconventional methods in ethnopharmacology". Journal of Ethnopharmacology 154, 2, 475.

Sõukand, Renata and Raivo Kalle (2013) "Where does the border lie: locally grown plants used for making tea for recreation and/or healing, 1970s-1990s Estonia". Journal of Ethnopharmacology 150, 1, 162-174. 
Sõukand, Renata and Raivo Kalle (2012a) "The use of teetaimed in Estonia, 1880s-1990s". Appetite 59, 523-530.

Sõukand, Renata and Raivo Kalle (2012b) "Personal and shared: the reach of different herbal landscapes". Estonian Journal of Ecology 61, 1, 20-36.

Sõukand, Renata and Raivo Kalle (2011) "Change in medical plant use in Estonian ethnomedicine: a historical comparison between 1888 and 1994". Journal of Ethnopharmacology 135, 2, 251260.

Sõukand, Renata and Raivo Kalle (2010a) "Herbal landscape. The perception of the landscape as a source of medicinal plants". Trames 14, 3, 207-226.

Sõukand, Renata and Raivo Kalle (2010b) "Plant as object within herbal landscape: different kinds of perception. Biosemiotics" 3, 3, 299-313.

Sutrop, Urmas (2001) "List task and a cognitive salience index". Field Methods 13, 3, 263-276.

Tardío, Javier (2010) "Spring is coming: the gathering and consumption of wild vegetables in Spain". In Ethnobotany in the New Europe: people, health and wild plant resources, 211238. Manuel Pardo-de-Santayana, Andrea Pieroni, and Rajindra Puri, eds. Oxford, UK: Berghahn Press.

Tardío, Javier, Manuel Pardo-de-Santayana, and Ramón Morales (2006) "Ethnobotanical review of wild edible plants in Spain". Botanical Journal of the Linnean Society 152, 27-72.

Tardío, Javier, Higinio Pascual, and Ramón Morales (2005) "Wild food plants traditionally used in the province of Madrid, Central Spain". Economic Botany 59, 122-136.

Turner, Nancy J., Łukasz Jakub Łuczaj, Paola Migliorini, Andrea Pieroni, Angelo Leandro Dreon, Linda Enrica Sacchetti, and Maurizio G. Paoletti (2011) "Edible and tended wild plants, traditional ecological knowledge and agroecology". Critical Reviews in Plant Sciences 30, 198-225.

Valk, Uno, ed. (1988) Eesti sood. [Estonian peatlands]. Tallinn: Valgus.

World Bank high-income economy. http://en.wikipedia.org/wiki/World_Bank_high-income_ economy Accessed 15.10.2014 